\title{
Effect of a Novel Clinical Decision Support Tool on the Efficiency and Accuracy of Treatment Recommen- dations for Cholesterol Management
}

Marianne R. Scheitel'; Maya E. Kessler²; Jane L. Shellum; Steve G. Peters³; Dawn S. Milliner; Hongfang Liu; Ravikumar Koman-

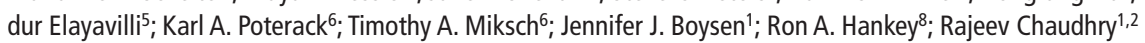

${ }^{1}$ Knowledge Management and Delivery Center, Mayo Clinic, Rochester, MN, USA;

${ }^{2}$ Division of Primary Care Internal Medicine, Mayo Clinic, Rochester, MN;

${ }^{3}$ Department of Medicine, Division of Pulmonary and Critical Care Medicine, Mayo Clinic, Rochester, MN;

${ }^{4}$ Department of Medicine, Division of Nephrology, Mayo Clinic, Rochester, MN;

${ }^{5}$ Division of Biomedical Statistics and Informatics, Mayo Clinic, Rochester, MN;

${ }^{6}$ Department of Anesthesiology, Mayo Clinic Hospital, Phoenix, AZ;

${ }^{7}$ Section of Applied Informatics, Department of Information Technology , Mayo Clinic, Rochester, MN;

${ }^{8}$ UDP Specialized Data Services, Mayo Clinic, Rochester, MN

\section{Keywords}

Clinical decision support system, ambulatory care information systems, testing and evaluation of health information technology, electronic health records, knowledge delivery, knowledge management

\section{Summary}

Background: The 2013 American College of Cardiology / American Heart Association Guidelines for the Treatment of Blood Cholesterol emphasize treatment based on cardiovascular risk. But finding time in a primary care visit to manually calculate cardiovascular risk and prescribe treatment based on risk is challenging. We developed an informatics-based clinical decision support tool, MayoExpertAdvisor, to deliver automated cardiovascular risk scores and guideline-based treatment recommendations based on patient-specific data in the electronic heath record.

Objective: To assess the impact of our clinical decision support tool on the efficiency and accuracy of clinician calculation of cardiovascular risk and its effect on the delivery of guideline-consistent treatment recommendations.

Methods: Clinicians were asked to review the EHR records of selected patients. We evaluated the amount of time and the number of clicks and keystrokes needed to calculate cardiovascular risk and provide a treatment recommendation with and without our clinical decision support tool. We also compared the treatment recommendation arrived at by clinicians with and without the use of our tool to those recommended by the guidelines.

Results: Clinicians saved 3 minutes and 38 seconds in completing both tasks with MayoExpertAdvisor, used 94 fewer clicks and 23 fewer key strokes, and improved accuracy from the baseline of $60.61 \%$ to $100 \%$ for both the risk score calculation and guideline-consistent treatment recommendation.

Conclusion: Informatics solution can greatly improve the efficiency and accuracy of individualized treatment recommendations and have the potential to increase guideline compliance. 


\section{Correspondence to:}

Rajeev Chaudhry, MBBS,MPH

Associate Professor of Medicine, Division of Primary

Care Internal Medicine

Knowledge and Delivery Center

Mayo Clinic

200 First Street SW

Rochester, MN 55905

TEL: (507) 255-3956

E-mail:Chaudhry.Rajeev@mayo.edu
Appl Clin Inform 2017; 8: 124-136

https://doi.org/10.4338/ACI-2016-07-RA-0114

received: July 15, 2016

accepted: December 2, 2016

published: February 8, 2017

Citation: Scheitel MR; Kessler ME; Shellum JL; Peters SG; Milliner DS; Liu H; Elayavilli RK; Poterack KA; Miksch TA; Boysen JJ; Hankey RA; Chaudhry R. Effect of a novel clinical decision support tool on the efficiency and accuracy of treatment recommendations for cholesterol management. Appl Clin Inform 2017; 8: 124-136

https://doi.org/10.4338/ACI-2016-07-RA-0114 


\section{Background And Significance}

Guideline compliance for the prevention and treatment of atherosclerotic cardiovascular disease (ASCVD) is suboptimal, even in the highest risk patients. This was true under the Adult Treatment Panel III (ATP III) guidelines in 2001 [1] and seems to be continuing under the 2013 American College of Cardiology (ACC) and the American Heart Association (AHA) guidelines [2]. This is despite the easy availability web-based individual cardiovascular risk score calculators such as the ACC risk calculator (tools.acc.org/ASCVD-Risk-Estimator/) to aid clinicians in calculating risk. To use such a calculator a clinician must manually enter data such as age, sex, race, blood pressure, hypertension history, smoking status, and cholesterol level.

One factor that may be contributing to the under treatment of high risk patients is the time and click burden for primary care clinicians to complete this calculation and determine the appropriate medication. One can presume from other observations of EHR navigation that this may be challenging [3-4]. The literature also suggests that there is inadequate time in a typical visit to gather information necessary for such a risk calculation [5-6]. Primary care also must address preventive services and chronic disease management. The U.S. Preventive Services Task Force estimated that a clinician would need 7.4 hours each day just to comply with guidelines for preventive services [6]. Another barrier is the current state of the EHR, containing an overwhelming amount of information in the clinical and structured data elements, not necessarily optimized for clinician workflow [3-4]. Significant time is spent interacting with the EHR trying to find relevant information and complete clinical documentation [7-8]. Further, information overload and the presentation of data in the health record may increase the number of clinical errors [9-11].

In order to automate the process of calculating risk and determining appropriate treatment, and hopefully thus improve the prevention and treatment of ASCVD, we have developed a clinical decision support tool, MayoExpertAdvisor (MEA), that provides cardiovascular risk scores and guideline-based treatment recommendations based on patient-specific data in the EHR. In this study, we aim to show that our clinical decision support tool improves the efficiency and accuracy of clinician calculation of cardiovascular risk and increases the rate at which clinicians provide guideline-consistent treatment recommendations.

Although similar tools to automate the delivery of cardiovascular risk scores and treatment recommendations and have been developed elsewhere [12-13], to our knowledge ours is the first to undergo a formal evaluation to test its effect on the efficiency and accuracy of clinician treatment recommendations. Additionally, our tool is likely the first to use data derived through natural language processing (NLP) and the first to present treatment recommendations alongside supporting data and links to educational resources and decision aids.

\section{Objectives}

The objective of this study is to assess the impact of MEA on the efficiency and accuracy of clinician calculation of cardiovascular risk as well as MEA's effect on the delivery of guideline-consistent treatment recommendations.

\section{Methods}

\subsection{Practice Setting}

The clinicians invited to participate in this study were from Employee and Community Health and Cardiology in Mayo Clinic, Rochester, Minnesota. Thirty-three clinicians of the eligible 262 including 13 primary care internal medicine physicians, 4 family medicine physicians, 10 internal medicine residents, and 6 cardiology nurse practitioners participated in the study. 


\subsection{Patient Selection}

Real patient data was used in this study to simulate MEA use in clinical practice. The patients in the study were selected from the Employee and Community Health population which consists of patients receiving primary care at Mayo Clinic, Rochester, MN.

We randomly selected patients who were not on the recommended dose of statin, determined by manual review. We looked at two groups of patients. The first group included 409 patients between the ages of 40 and 75 with an LDL greater than 190mg/dL and no history of ASCVD. The second group included 3880 diabetic patients between the ages of 40 and 75 with an LDL over $70 \mathrm{mg} / \mathrm{dL}$ or Non-HDL over 100 and no history of ASCVD. We selected four patients randomly from each group, and these 8 patients were used for the test scenarios in the study.

\subsection{MEA System Description}

MEA provides care recommendations that are established by care process models (CPMs) in AskMayoExpert, an internal resource designed for point of care knowledge delivery. The knowledge of the CPMs is based on the most recent guidelines and input from subject matter experts. The CPMs are presented as flow-charts so that clinicians may proceed through each decision point until they arrive at the appropriate care recommendation. Embedded within the CPMs are risk score calculators and links to relevant patient education materials. Our CPM for the management of cholesterol differs only minimally from the recommendations of the 2013 ACC/AHA guidelines [2].

The clinical data needed to automate the care processes come from diverse sources including multiple EHR and internal specialty specific applications ( $>$ Figure 1). Both structured data and unstructured data concepts are extracted from the clinical notes via natural language processing (NLP). In order to collect and deliver the data in one service layer, a unified data platform (UDP) has been developed at Mayo Clinic. The UDP serves as a composite data source that is needed to execute the rules for the MEA initiative.

The identification of data needed at each node in the CPMs and the clinical logic portrayed therein was translated into programmable logic utilizing a collaborative effort between clinicians, informaticians, and technologists. Using C\#.NET, this logic was encoded into a rules engine.

A web service for the ACC/AHA ASCVD risk calculator is prefilled with data from the EHR to determine the risk for a given patient. The user interface provides a risk score when MEA is accessed ( Figure 2). The user interface also allows users to modify the data parameters in the calculator and see the effect on patient risk for ASCVD without affecting data in the EHR ( $>$ Figure 3).

Finally the system delivers individualized care recommendations based on patient-specific data from the EHR and the knowledge from the CPMs ( $>$ Figure 2). In addition to the recommended clinical action, the user interface also delivers automated risk score calculations and access to relevant patient education materials and shared decision-making tools. MEA is integrated into the locally produced EHR in order to limit the number of applications that clinicians need to open during patient encounters. Mayo Clinic's EHR is in a general electric (GE) centricity environment. To improve the user interface Mayo Clinic has developed a viewer called Synthesis that used GE web services to retrieve data and present it to clinicians in a more intuitive format. MEA has been interfaced with the Synthesis thus enabling easy navigation for the clinicians to the risk score and any recommendations regarding cholesterol management.

\subsection{Study design and data collection}

Each clinician was given a set of instructions, which asked them to look at two randomly selected patient records, one patient record from each group previously described. The clinicians were asked to calculate the ASCVD risk score and recommend treatment for each patient based on EHR review with or without input from MEA. The patient group for which MEA input was given was switched every other clinician so that time differences could not be attributed to different patient characteristics.

Each clinician performed the assigned tasks on a computer with Morae software (v 3.3.3, TechSmith Corporation, Okemos, MI). Using Morae, the following efficiency metrics were collected: 
time, number of clicks, and number of key strokes. In addition, we compared the clinicians' ASCVD risk score calculations to the pre-calculated scores given by MEA and noted whether the care recommendation matched the suggested care on the hyperlipidemia CPM.

\subsection{Survey}

A survey regarding the ASCVD risk score calculator and satisfaction withthe MEA tool were administered following the completion of the study through Morae. The survey questions are in Table 4 .

\subsection{Statistics}

The patient populations and data characterisics were compared using t-tests and a two-sided test with a significance $<0.05$ on $\mathrm{JMP}^{\circ}$ (v 10.0.0, SAS Instittue Inc, Cary, NC).

A t-test was used to compare the amount of time with and without assistance from MEA. ANOVA was used to compare the amount of time it took between clinician type. These tests were performed on SAS 9.3 (SAS Institute, Cary NC).

\section{Results}

The characteristics of the patient data used in this study is shown in $>$ Table 1 . Because some patients were used more frequently in the study than others due to patient data changing during the time of the study, we confirmed that there was no selection bias by analyzing the patient data characteristic and finding no statistical differences between populations.

\subsection{Time spent making calculation and recommendation}

Without any assistance from MEA, the clinicians spent an average of 4 minutes and 21 seconds to calculate the ASCVD score and a total of 5 minutes and 8 seconds to additionally determine the care they would recommend for the patient. Qualitatively, some clinicians took a lot of time scrolling through previous notes to find parameters such as blood pressure rather than looking in parts of the EHR with discrete data, such as looking in the vitals section. With MEA, the clinicians spent 39 seconds to calculate the ASCVD score and a total of 1 minute and 31 seconds to calculate the ASCVD score and determine a recommendation for patient care. The clinicians saved 3 minutes and $42 \mathrm{sec}-$ onds in calculating the ASCVD score and a total of 3 minutes and 38 seconds in determining the recommendation. The time savings were statistically significant.

A break out summary comparing the time required to complete the tasks with and without the use of MEA is found in Table 2. We analyzed statistical significance across clinician types. We found that when clinicians did not use MEA there was statistical significance $(\mathrm{p}<0.05)$ in the total amount of time for calculation and recommendation between nurse practitioners and physician assistants and all other clinicians types. There was also a statistically significant difference between the residents and the internal medicine physicians. However, usage of MEA resulted in no statistical difference across clinician types.

\subsection{Efficiency of clicks and key strokes making calculation and recom- mendation}

Without any assistance from MEA, clinicians have to go through the EHR clicking on multiple tabs in order to find relevant data. The quantiative nature of this time and click burden and the significantly improved the efficiency of this process is shown in $>$ Table 3. 


\subsection{Accuracy of calculation and recommendation}

The clinicians were found to have a $60.61 \%$ accuracy of ASCVD risk score calculation and $60.61 \%$ accuracy in selecting the guideline recommended statin treatment without MEA. The clinicians had a 100\% accuracy of ASCVD risk score calculation and 100\% accuracy in selecting the guideline recommended statin treatment with the use of MEA. The gold-standard for ASCVD risk score and guideline-recommended treatment was the MEA output which was verified by the study team to ensure accuracy. There was no statistical difference in accuracy by type of clinician.

The most frequent errors that clinicians made in calculating the ASCVD risk score were not using the most recent blood pressure (41.7\%) and incorrectly determining whether the patient was being treated for hypertension (33.3\%). Clinicians also inputted the wrong gender, age, and smoking status.

\subsection{Survey Results}

Of the clinicians surveyed, 51.5\% indicated they calculate ASCVD risk most of the time or always, and $27.3 \%$ indicated that a high 30 year risk score may affect initiating treatment. Fewer than half of the clinicians used the risk calculator to encourage patients to quit smoking (45.4\%) and lower blood pressure or cholesterol (46.8\%). The questions and results regarding clinician perception of ASCVD risk score utility and general satisfaction with MEA are given in Table 4.

\section{Discussion}

In this study we observed not only significant savings in time and efficiency, but also marked improvement in the overall accuracy for a clinician to calculate an ASCVD risk score and determine appropriate cholesterol treatment using MEA. Clinicians saved 3 minutes and 38 seconds in completing both tasks with MEA, were more efficient with 94 fewer clicks and 23 fewer key strokes with MEA, and improved accuracy from the baseline of $60.61 \%$ for both the risk score calculation and treatment recommendation. On average, there are 62 patients not on optimal cholesterol treatment seen in the Mayo Clinic primary care practice each day. If time savings is estimated only based on patients who need treatment, MEA would save the practice 3 hours and 45 minutes each day - approximately one half day of clinician time.

Providing care to patients in a timely and accurate manner is challenging when there is an overload of information [10]. We observed the types and frequency of errors that can occur with manual entry into a calculator, i.e. almost $40 \%$ of calculations were erroneous due to input of wrong information. For example, clinicians sometimes selected the wrong blood pressure reading from the $\mathrm{EHR}$, or missed that a patient was on anti-hypertensive treatment, and thus chose the wrong field in the ACC risk score. With this knowledge delivery solution, data can be extracted automatically from the EHR and can populate the ACC risk score calculator to help clinicians deliver individualized treatment recommendations for patients with elevated cardiovascular risk. Only $15 \%$ of the clinicians in this study indicated that they always will calculate a patient's ASCVD risk score and this suggests that technology can have an integral role in ensuring consistent and accurate delivery of individualized recommendations.

One of the challenges in delivering electronic knowledge recommendations from clinical guidelines has been ensuring it fits the clinician's workflow [14]. Even though we have not yet evaluated MEA in clinical practice, the brief survey at the end of our encounter suggested a positive perception of the user interface and design ( $>$ Table 4 ). Further analysis of clincian satisfaction will be needed when MEA is implemented in practice.

An important limitation of this study is that this was conducted in a simulated clinical environment. Clinicians searched the EHR for evidence of smoking, race, etc. in calculating the ASCVD score, but in a true patient encounter, the clinician would have some of this information upon history taking and clinicians typically know patients' medical histories reducing the amount of information that needs to be looked up. However, a clinical environment is also prone to more distractions and interruptions. Another limitation is small sample size. However, the objectively large time 
saving and statistical significance of these findings suggest broad applicability. Further MEA is currently only integrated useI n Mayo's internally produced EHR viewer Synthesis. Moreover, there are plans to integrate MEA in Cerner for other Mayo Clinic sites, and to EPIC as Mayo transitions to this EHR.

\section{Conclusion}

Our study demonstrates opportunity for electronic knowledge delivery solutions to improve efficiency by decreasing the amount of time and the number of clicks for information retrieval required for individualized risk calculation and to increase the accuracy in the delivery of guideline-consistent treatment recommendations for reduction of cardiovascular risk by primary care clinicians.

\section{Multiple Choice Questions}

Clinical Decision Support Systems:

a) Can improve accuracy of calculation of individual risk scores

b) Can improve efficiency of clinicians by automating the task of manually entering data into scoring tools

c) Support clinician decision making, but allow clinicians to use their own judgments

d) All of the above

American College of Cardiology/American Heart Association atherosclerotic cardiovascular disease risk calculator includes which of the following:

a) Presence of diabetes mellitus

b) Systolic blood pressure

c) Smoking status

d) All of the above

\section{Clinical Relevance Statement}

The current study demonstrates significant time savings and potential improvement in guideline compliance for the treatment of cholesterol by primary care clinicians. Further development of clinical decisional support tools, such as MEA, have the potential to save time and to improve care in concordance with best practice, evidence based guidelines for more complex clinical issues.

\section{Conflict Of Interest}

The authors report no conflict of interest relationships to industry.

\section{Protection Of Human And Animal Subjects}

Mayo Clinic's Institutional Review Board approved this study.

\section{Acknowledgement}

We are grateful to the American College of Cardiology for providing a web service to access the pooled cohort data.

\section{Contributors}

M.R.S. performed data analysis and manuscript prepration. R.C. and T.A.M. helped with the design of the study and manuscript prepration. R.A.H. performed data collection and manuscript prepration. M.E.K., J.L.S., S.G.P., H.L., R.K.E, K.A.P., D.S.M. and J.J.B. All analyzed results and participated in manuscript prepration. 


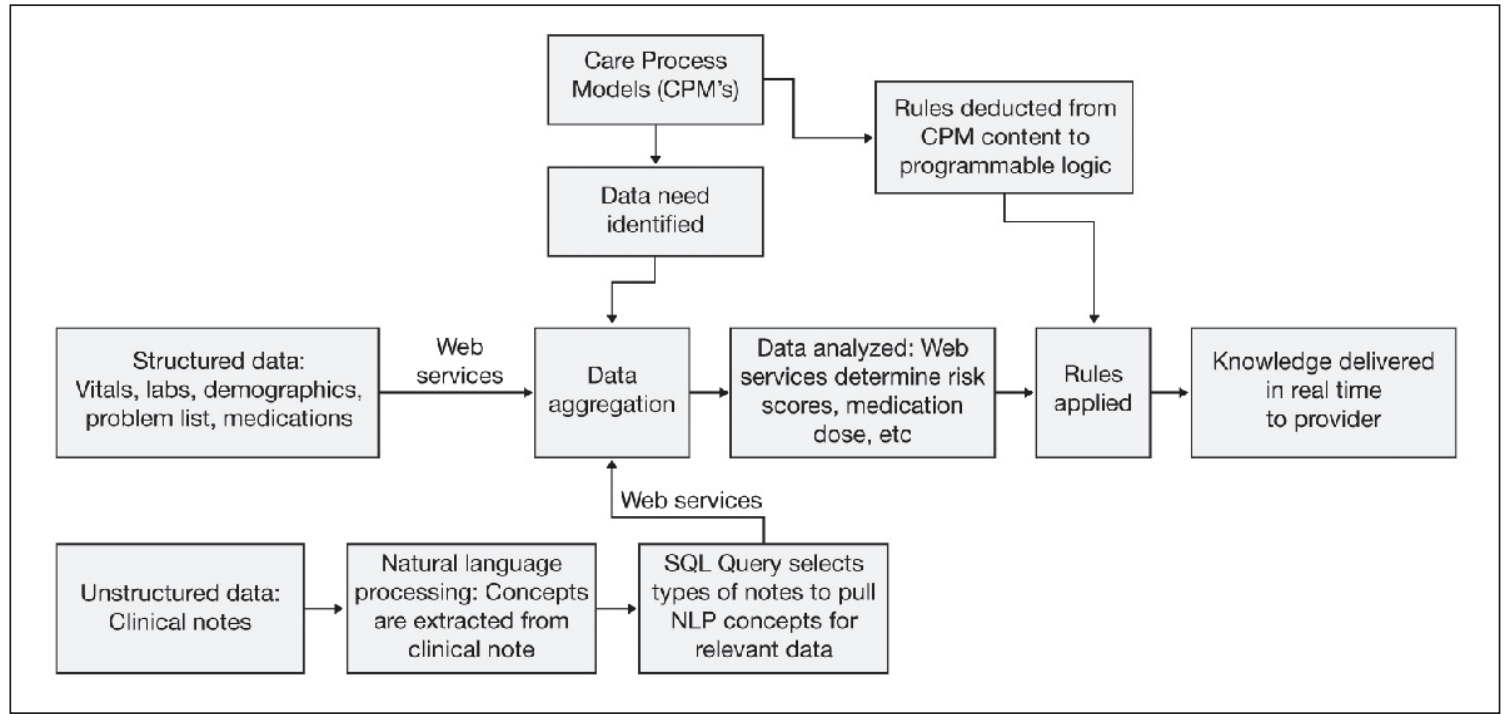

Fig. 1 Architecture Diagram of MEA System 
MayoExpertAdvisor Patient-specific care recommendations and knowledge resources.

Testing, Adam
Blood Pressure
$112 / 70 \mathrm{~mm} / \mathrm{Hg} 28$-Apr-2014
Heart Rate
$76 \mathrm{bpm} 28$-Apr-2014
Weight
$85 \mathrm{~kg} 28$-Apr-2014
BMI
31.2 28-Apr-2014
Primary Physician
John Smith, M.D.
Refresh data
Feedback
Please help improve this
product by providing feedback.

Conditions (

Atrial Fibrillation

$\rightarrow$ Gare Recommendation:

Consider anticoagulant therapy due to $\mathrm{CHA}_{2} \mathrm{DS}_{2}$-VASc score 2 or greater

View details and knowledge resources $\checkmark$

\section{Congestive Heart Failure with Reduced Ejection Fraction \\ $\rightarrow$ Care Recommendation: \\ Initiate ACE inhibitor or ARB due to heart failure}

View details and knowledge resources $\checkmark$

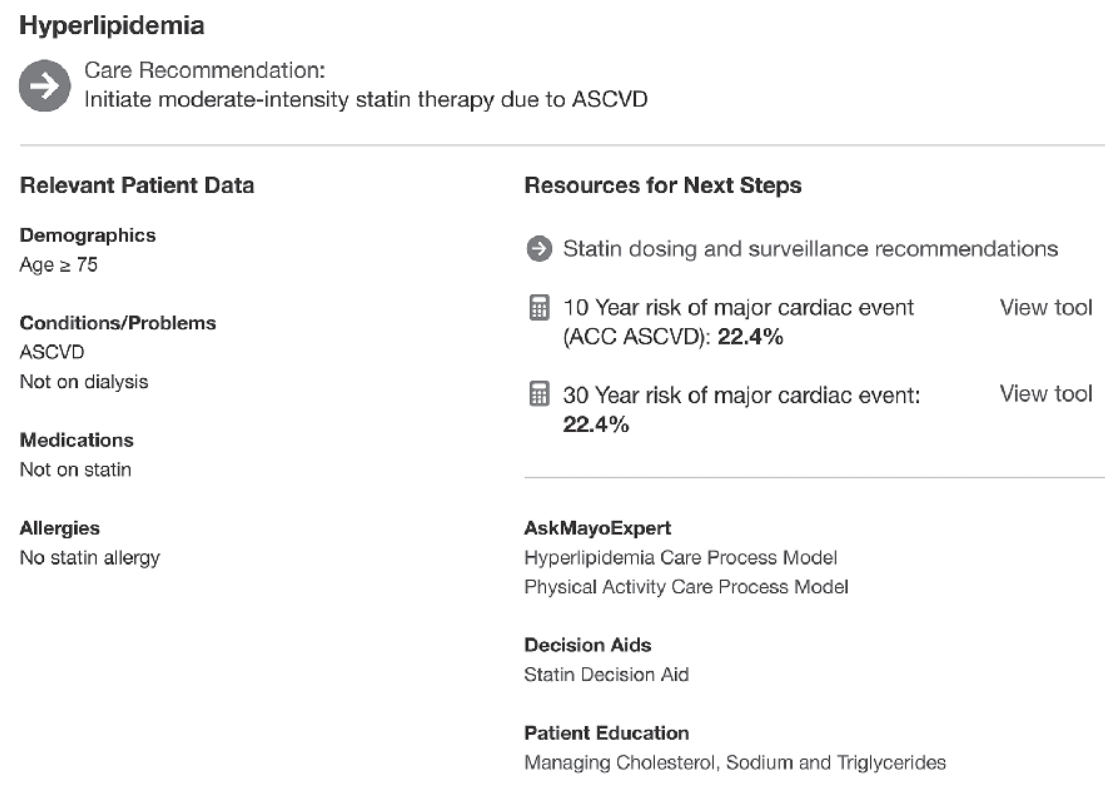

Hide details and knowledge resources $\wedge$

Fig. 2 MayoExpertAdvisor User Interface: Interface includes care recommendation, risk score, and relevant patient data. 
Individualized Knowledge Page Patient-specific care recommendations and knowledge resources.

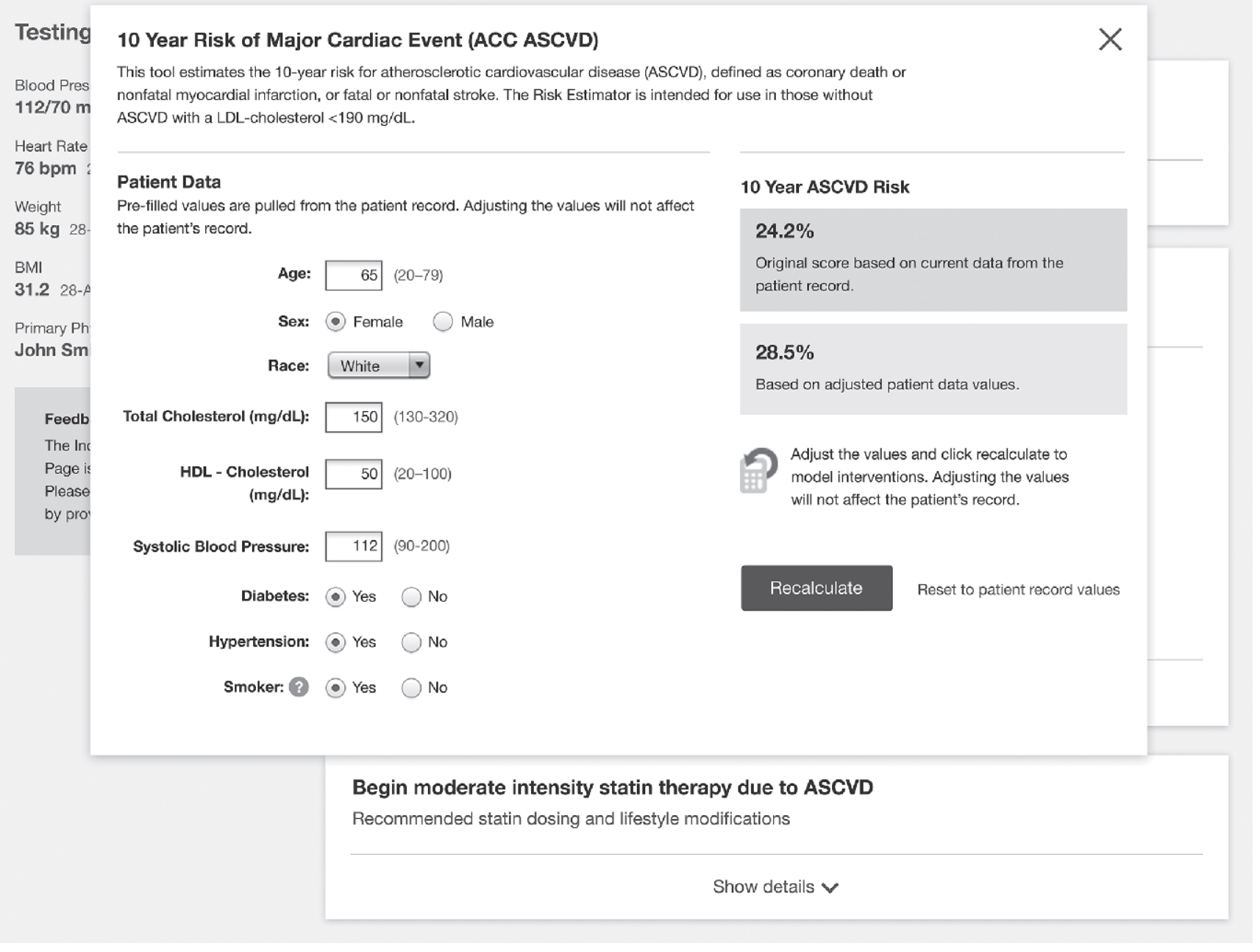

Fig. 3 Risk Calculator Interface: Risk calculator pulls data from EHR and allows the user to do "what if" scenarios without affecting the data in the EHR. 
Table 1 Characteristics of patient data used with and without MEA

\begin{tabular}{|l|c|c|l|}
\hline Patient Characteristic & No MEA & MEA & p value \\
\hline Mean Number of medications (SD) & $7.7(4.9)$ & $8.2(5.4)$ & 0.61 \\
\hline Document Count & $170.3(95.5)$ & $172.4(91.6)$ & 0.93 \\
\hline Appointment Count & $40.1(22.2)$ & $40.3(22.0)$ & 0.98 \\
\hline Hospital Days & $0.1(0.3)$ & $0.1(0.33)$ & 0.71 \\
\hline Height Count & $4.8(2.0)$ & $4.8(2.0)$ & 0.9 \\
\hline Weight Count & $8.3(5.1)$ & $8.4(5.0)$ & 0.98 \\
\hline Pulse Count & $10.8(7.7)$ & $10.7(7.6)$ & 0.98 \\
\hline BP Count & $11.5(8.7)$ & $11.5(8.5)$ & 0.97 \\
\hline Lab Count & $112.6(89.6)$ & $110.1(88.0)$ & 0.93 \\
\hline
\end{tabular}

Table 2 Amount of Time to Complete Tasks

\begin{tabular}{|c|c|c|c|c|c|c|c|c|c|}
\hline \multirow[t]{2}{*}{$\begin{array}{l}\text { Clinician } \\
\text { Type }\end{array}$} & \multirow[t]{2}{*}{ Task } & \multicolumn{3}{|l|}{$\begin{array}{l}\text { No MEA } \\
\text { (in sec) }\end{array}$} & \multicolumn{3}{|l|}{$\begin{array}{l}\text { With MEA } \\
\text { (in sec) }\end{array}$} & \multirow{2}{*}{$\begin{array}{l}\mid \Delta \\
\text { Time|Mean } \\
\text { (STD) }\end{array}$} & \multirow[t]{2}{*}{$\operatorname{Pr}>|t|$} \\
\hline & & Mean (STD) & Min & Max & Mean (STD) & Min & Max & & \\
\hline \multirow{2}{*}{$\begin{array}{l}\text { All Clinicians } \\
(\mathrm{N}=33)\end{array}$} & ASCVD Calculation & $261(75)$ & 144 & 465 & $37(19)$ & 16 & 80 & $222(74)$ & $<0.0001$ \\
\hline & $\begin{array}{l}\text { Total Time for } \\
\text { Recommendation }\end{array}$ & $308(101)$ & 155 & 611 & $91(33)$ & 49 & 173 & $218(98)$ & $<0.0001$ \\
\hline \multirow{2}{*}{$\begin{array}{l}\text { CNP/PA } \\
(\mathrm{N}=6)\end{array}$} & ASCVD Calculation & $342(93)$ & 193 & 465 & $31(8)$ & 19 & 43 & $310(92)$ & 0.0004 \\
\hline & $\begin{array}{l}\text { Total Time for } \\
\text { Recommendation }\end{array}$ & $437(129)$ & 250 & 611 & $93(17)$ & 77 & 126 & $343(115)$ & 0.0008 \\
\hline \multirow{2}{*}{$\begin{array}{l}\text { Resident } \\
(\mathrm{N}=10)\end{array}$} & ASCVD Calculation & 197(33) & 144 & 252 & $29(7)$ & 20 & 47 & $168(35)$ & $<0.0001$ \\
\hline & $\begin{array}{l}\text { Total Time for } \\
\text { Recommendation }\end{array}$ & 230(53) & 155 & 317 & $77(29)$ & 37 & 105 & $153(71)$ & $<0.0001$ \\
\hline \multirow{2}{*}{$\begin{array}{l}\text { Staff-Family } \\
\text { Medicine } \\
(\mathrm{N}=4)\end{array}$} & ASCVD Calculation & $286(66)$ & 196 & 348 & $38(13)$ & 24 & 46 & $248(66)$ & 0.0049 \\
\hline & $\begin{array}{l}\text { Total Time for } \\
\text { Recommendation }\end{array}$ & $314(68)$ & 235 & 391 & $97(38)$ & 60 & 137 & $216(32)$ & 0.0009 \\
\hline \multirow{2}{*}{$\begin{array}{l}\text { Staff-Internal } \\
\text { Medicine } \\
(\mathrm{N}=13)\end{array}$} & ASCVD Calculation & 266(49) & 182 & 336 & $50(24)$ & 16 & 88 & $216(50)$ & $<0.0001$ \\
\hline & $\begin{array}{l}\text { Total Time for } \\
\text { Recommendation }\end{array}$ & 307 (59) & 219 & 420 & $98(40)$ & 49 & 173 & $210(67)$ & $<0.0001$ \\
\hline
\end{tabular}

Table 3 Efficiency Metrics

\begin{tabular}{|l|l|c|l|l|l|}
\hline Clinician Type & Task & Mean Number (Standard Deviation) \\
\cline { 3 - 6 } & & No MEA & With MEA & $|\Delta|$ & Pr $>|\mathbf{t}|$ \\
\hline Clicks (N=24) & ASCVD Calculation & $88(67)$ & $1.2(1.0)$ & $87(67)$ & $<0.0001$ \\
\cline { 2 - 6 } & Total for Recommendation & $101(85)$ & $6.6(4.1)$ & $94(84)$ & $<0.0001$ \\
\hline Key strokes (N=24) & ASCVD Calculation & $25(36)$ & $1.5(4.2)$ & $24(37)$ & 0.0046 \\
\cline { 2 - 7 } & Total for Recommendation & $27(38)$ & $5.2(4.8)$ & $22(40)$ & 0.0132 \\
\hline
\end{tabular}


Table 4 Survey of providers perception on ASCVD risk score utility

\begin{tabular}{|c|c|c|c|c|c|}
\hline $\begin{array}{l}\text { Survey of providers perception on ASCVD } \\
\text { risk score utility and MEA prototype }\end{array}$ & Always & $\begin{array}{l}\text { Most of } \\
\text { the Time }\end{array}$ & Sometimes & Rarely & Never \\
\hline $\begin{array}{l}\text { 1. How often would you calculate the ASCVD risk } \\
\text { score for a given patient if it were not pre-calcu- } \\
\text { lated for you? }\end{array}$ & $15.1 \%$ & $36.4 \%$ & $36.4 \%$ & $12.1 \%$ & $0.0 \%$ \\
\hline $\begin{array}{l}\text { 2. Would a high } 30 \text { year risk score ( }>30 \% \text { ) in- } \\
\text { fluence your likelihood of initiating statin therapy } \\
\text { if a patient's } 10 \text { year risk score is low? Note that } \\
\text { the } 30 \text { year risk score applies to patients ages } \\
20-59 \text { years. }\end{array}$ & $0.0 \%$ & $27.3 \%$ & $55.6 \%$ & $18.2 \%$ & $0.0 \%$ \\
\hline $\begin{array}{l}\text { 3. Do you use the ASCVD risk score calculator to } \\
\text { encourage patients to quit smoking? }\end{array}$ & $15.1 \%$ & $30.3 \%$ & $27.3 \%$ & $18.2 \%$ & $9.1 \%$ \\
\hline $\begin{array}{l}\text { 4. Do you use the ASCVD risk score calculator to } \\
\text { encourage patients to lower blood pressure and } \\
\text { cholesterol through exercise? }\end{array}$ & $18.7 \%$ & $28.1 \%$ & $31.2 \%$ & $15.6 \%$ & $6.2 \%$ \\
\hline 5. I am able to trust the pre-calculated risk scores. & $71.9 \%$ & $25.0 \%$ & $3.1 \%$ & $0.0 \%$ & $0.0 \%$ \\
\hline 6. I am able to trust the care recommendation. & $59.4 \%$ & $25.0 \%$ & $12.5 \%$ & $0.0 \%$ & $3.1 \%$ \\
\hline $\begin{array}{l}\text { 7. The care recommendations displayed on the In- } \\
\text { dividualized Knowledge Page (IKP/MEA) are easy } \\
\text { to understand. }\end{array}$ & $75.8 \%$ & $18.2 \%$ & $6.1 \%$ & $0.0 \%$ & $0.0 \%$ \\
\hline $\begin{array}{l}\text { 8. The layout of the information is logically organ- } \\
\text { ized for providing patient care. }\end{array}$ & $69.7 \%$ & $24.2 \%$ & $6.1 \%$ & $0.0 \%$ & $0.0 \%$ \\
\hline
\end{tabular}




\section{References}

1. Expert Panel on Detection, Evaluation and Treatment of High Blood Cholesterol in Adults. Executive summary of the third report of the National Cholesterol Education Program (NCEP) expert panel on Detection, Evaluation, and Treatment of high blood cholesterol in adults (Adult Treatment Panel III). JAMA 2001; 285(19): 2486.

2. Stone NJ, Robinson, JG, Lichtenstein, AH, Bairey Merz CN, Blum CB, Eckel RH, Goldberg AC, Gordon D, Levy D, Lloyd-Jones DM, McBride P, Schwartz JS, Shero ST, Smith SC, Watson K, Wilson PWF. 2013 ACC/AHA guideline on the treatment of blood cholesterol to reduce atherosclerotic cardiovascular risk in adults. JACC 2014; 63(25_PA): 2889-2934.

3. Koopman RJ, Steege LMB, Moore JL, Clarke MA, Canfield SM, Kim MS, Belden JL (2015). Physician Information Needs and Electronic Health Records (EHRs): Time to Reengineer the Clinic Note. J Am Board Fam Med 2015; 28(3): 316-323.

4. Tange HJ. The paper-based patient record: Is it really so bad? Comput Methods Programs Biomed 1995; 48(1): 127-131.

5. Linzer M, Konrad TR, Douglas J, McMurray JE, Pathman DE, Williams ES, Schwartz MD, Gerrity M, Scheckler W, Bigby JA, Rhodes E. Managed care, time pressure, and physician job satisfaction: results from the physician worklife study. J Gen Intern Med 2003; 15(7): 441-450.

6. Yarnall KS, Pollak KI, Ostbye T, Krause KM, Michener, JL. Primary care: is there enough time for prevention? Am J Public Health 2003; 93(4): 635-641.

7. Oxentenko AS, West CP, Popkave C, Weinberger SE, Kolars, JC. Time spent on clinical documentation: a survey of internal medicine residents and program directors. Arch Intern Med 2010; 170(4): 377-380.

8. Shipman SA, Sinsky CA. Expanding primary care capacity by reducing waste and improving the efficiency of care. Health Aff 2013; 32(11): 1990-1997.

9. Ahmed A, Chandra S, Herasevich V, Ognjen G, Pickering BW. The effect of two different electronic health record user interfaces on intensive care provider task load, errors of cognition, and performance. Crit Care Med 2011; 39(7): 1626-1634.

10. Ash JS, Berg M, Coiera E. Some unintended consequences of information technology in health care: the nature of patient care information system-related errors. J Am Med Inform Assoc 2004; 11(2): 104-112.

11. Meeks DW, Smith MW, Taylor L, Sittig DF, Scott JM, Singh H. An analysis of electronic health record-related patient safety concerns. J Am Med Inform Assoc 2014; 21(6): 1053-1059.

12.Wang SV, Rogers JR, Jin Y, Bates DW, and Fischer MA. Use of electronic healthcare records to identify complex patients with atrial fibrillation for targeted intervention. JAMIA 2016; ocw082.

13. Persell, SD, Dunne AP, Lloyd-Jones DM, Baker DW. Electronic health record-based cardiac risk assessment and identification of unmet preventive needs. Med Care 2009; 47(4): 418.

14. Maviglia SM, Zielstorff RD, Paterno M, Teich JM, Bates DW, Kuperman GJ. Automating complex guidelines for chronic disease: lessons learned. J Am Med Inform Assoc 2003; 10(2); 154-165. 